\section{In Support of Call for Improvement in Aboriginal Child Health}

Dear Editor:

Smylie et al. ${ }^{1}$ have done a signal service to Canada's Aboriginal peoples and to health care professionals who care for their children or may be called upon to do so. Accurate information is essential to health care planning and management, and the authors clearly demonstrate the need for improvement in this regard.

Their recommendations are constructive and need to be heeded by public authorities. The differences in neonatal and particularly postneonatal mortality rates between Aboriginal and non-Aboriginal Canadians must be causes of concern and of action. The Canadian Institute of Child Health has a long history of preoccupation with Aboriginal child health and is very much on the authors' wavelength.

The Prime Minister recently stated that maternal and child health were to have priority in Canada's foreign aid policy. The $\mathrm{CICH}$ immediately sought to point out that the same needs to be true of domestic policy, and that Aboriginal maternal and child health require particular preoccupation and action.

Smylie et al. have also underlined the indispensable value of accurate census information.

Some twenty-five years ago, Toronto pharmacist and philanthropist Murray Koffler brought together a group of conscientious people and created the Canadian Council for Aboriginal Business, in which Aboriginals and non-Aboriginals work together to achieve diversification of Aboriginal economies, of marketing strategies for their products and services, and of educational and training opportunities for their youth. The CICH urges that people of goodwill come together and create a comparable initiative in the health care field.

Robin Moore-Orr, DSc, RD

Chair, CICH Board of Directors

Victor C. Goldbloom, MD

Chair, CICH Advisory Council

\section{REFERENCE}

1. Smylie J, Fell D, Ohlsson A and the Joint Working Group on First Nations, Indian, Inuit, and Métis Infant Mortality of the Canadian Perinatal Surveillance System. A review of Aboriginal infant mortality rates in Canada: Striking and persistent Aboriginal/non-Aboriginal inequities. Can J Public Health 2010;101(2):143-48.

\section{Authors' Response:}

We thank Drs. Moore-Orr and Goldbloom for their letter on behalf of the Canadian Institute of Child Health regarding our systematic review of Aboriginal infant mortality in Canada, in which we highlighted striking and persistent Aboriginal/non-Aboriginal infant mortality rate disparities and identified significant gaps in the quality and coverage of Aboriginal infant mortality surveillance in Canada.

It is commendable that Canada's Prime Minister is championing the reduction of unnecessary and preventable maternal and child illness and death internationally as part of the G8/G20 summits. This position is in keeping with the United Nations Convention on the Rights of the Child, which all of the G8/G20 countries, including Canada, have signed.

In particular, as part of Article 24 of the UN Convention on the Rights of the Child, a commitment has been made to diminish infant and child mortality; to ensure that all children have access to medical assistance, primary health care, preventive health care, adequate nutritious food, and clean drinking water; and that their mothers can access pre- and postnatal health care. As people look to Canada for leadership on this issue, we need to be prepared for international attention on our domestic situation. After reviewing the situation for Aboriginal infants and their families in Canada, we are convinced that we could be doing things better together.

The policy recommendations in our review focus on the need to reduce Aboriginal/non-Aboriginal disparities in the social determinants of Aboriginal infant and child health; ensure equitable access for Aboriginal infants and their families to primary and tertiary health care services and preventive health care programs; and collect the necessary scientific information to ensure these services and programs are effective. This would include surveillance systems that accurately and appropriately identify First Nations (Status Indians living on-reserve), Status and non-Status Indians living offreserve, Inuit, and Métis infants at birth.

We welcome the idea of working in partnership with others to plan and implement the changes that are urgently needed to ensure that all infants born in Canada are able to exercise their right to the enjoyment of the highest attainable standard of health. We view this as a joint responsibility, not only of Aboriginal organizations and the federal and provincial governments but also of broader Canadian society. We look forward to following up with the Canadian Institute of Child Health on their suggested initiative and would urge all "others of goodwill" to be in touch with us sooner rather than later so that we can quickly move forward. Together we can make a difference.

Janet Smylie, Research Scientist, Centre for Research on Inner City Health, Saint Michael's Hospital and Associate Professor, Dalla Lana School of Public Health, University of Toronto, Toronto, ON

Mary Simon, President, Inuit Tapiriit Kanatami

Betty Ann Lavallée, National Chief, Congress of Aboriginal Peoples

Arne Ohlsson, Honorary Consultant Department of Paediatrics, Mount Sinai Hospital, Toronto and Professor emeritus, Departments of Paediatrics, Obstetrics \& Gynaecology and Health Policy, Management \& Evaluation, University of Toronto, Toronto, ON 